\title{
O NEGOCIADO SOBRE O LEGISLADO: O SINDICALISMO AINDA SOBREVIVE?
}

THE NEGOTIATION ON LEGISLATION: IS THE TRADE UNIONISM STILL SURVIVING?

Leandro Henrique Costa Bezerra ${ }^{1}$

\section{RESUMO}

A manutenção do direito ao trabalho digno diante da prevalência do negociado sobre o legislado somente se concebe por meio do artigo 7, caput, da Carta Magna, o qual protege os direitos mínimos ao trabalhador contra o retrocesso social. O presente artigo apresenta a necessidade de uma interpretação conforme a Constituição e as normas internacionais como requisito da sobrevivência dos sindicatos, após vigência da Lei n. ${ }^{\circ}$ 13.467/2017, a Reforma Trabalhista, que instituiu o negociado sobre o legislado. Por meio do método jurídico-projetivo, apresentamse reflexões sobre a sobrevivência dos sindicatos e o poder de negociação de cláusulas mais favoráveis à categoria.

Palavras-chave: sindicato, negociado sobre legislado, autonomia coletiva.

\begin{abstract}
The maintenance of the right to decent work in the face of the prevalence of the negotiation on legislation is only conceived through article 7, caput, of the Constitution, which protects the minimum rights to the worker against social retrogression. This article presents the need for an interpretation according to the Constitution and international rules as a requirement for the survival of the unions, after the validity of Law n. ${ }^{\circ} 13.467 / 17$, the Labor Reform, which established the negotiation on legislation. From the legal-projective method, there are reflections on the survival of unions and the negotiating power of clauses more favorable to the category.
\end{abstract}

Keywords: trade union, negotiation on legislation, collective autonomy.

\section{INTRODUÇÃO}

A consolidação dos direitos fundamentais no Estado Democrático de Direito consiste em garantir o mínimo de condições necessárias para o convívio social para todos os grupos, com foco nas relações humanas. A atuação sindical corresponde à proteção dos direitos de sua categoria, em convergência ao direito fundamental ao trabalho digno. Todavia, diante do avanço neoliberal em contexto de crise econômica, o processo de desregulamentação, ou seja, o não intervencionismo estatal, se dá para ampliar o poder sindical a ponto de criar normas balizadoras das relações de trabalho.

De início, a óptica do negociado sobre o legislado ganhou espaço na década de 1990, com a aprovação do Projeto de Lei (PL) nº 5.483/01 pela Câmara dos Deputados, o qual permitia uma flexibilização do art.618, §1, da Consolidação das Leis do Trabalho (CLT). Nesse aspecto, o negociado prevalecia sobre o legislado, "ressalvados direitos constitucionais mínimos, lei

\footnotetext{
1 Advogado. Especialista em Direito e Processo do Trabalho pelo Instituto de Direito Público (IDP). Bacharel em Direito pela Universidade de Brasília (UnB). Membro do Grupo de Pesquisa "Trabalho, Constituição e Cidadania" da Faculdade de Direito da Universidade de Brasília (UnB).
} 
complementar, Programa de Alimentação do Trabalhador - PAT, vale-transporte, FGTS e as normas de medicina e segurança do trabalho" (STUDART, 2019, p. 37).

Contudo, com a eleição do Presidente Lula, este solicitou a retirada e o arquivamento do projeto (convertido no PL n. ${ }^{0}$ 134/2001) no Senado Federal. Somente em 2017 a primeira flexibilização legal na ideia do negociado sobre o legislado foi aprovada, e entre as mudanças foi introduzido o art. 611-A e o art. 611-B da CLT. Era o PL n. ${ }^{\circ}$ 6.787/2016 da Reforma Trabalhista, transformada na Lei n. ${ }^{\circ} 13.467 / 2017$, sancionada pelo então Presidente Michel Temer.

Assim, as mudanças trazidas pela reforma, como a ampliação do poder de negociação e a instituição da contribuição sindical facultativa (AGUIAR, 2018) certificam o darwinismo social dos sindicatos ${ }^{2}$, representado pela capacidade de mudança constante das demandas sindicais. Isso impulsiona o papel político dos sindicatos na conquista de direitos aos trabalhadores representados pela categoria, a fim de obter receita e pautas para fontes de negociação.

Neste artigo, tem-se por estratégica metodológica a pesquisa teórica pela conexão da legislação trabalhista com aspectos doutrinários. Pelo método jurídico-projetivo, as condições vigentes para detecção de tendências futuras acerca da sobrevivência do sindicato e da força da negociação ganham destaque (GUSTIN; DIAS, 2006).

O objetivo desta pesquisa é apresentar alternativas para a sobrevivência dos sindicatos diante das alterações legislativas, em especial a lógica do negociado sobre o legislado, introduzida pelos artigos 611-A e 611-B da CLT. Ademais, a participação do sindicato na melhoria das condições de trabalho da categoria pode ser feita por meio da elaboração de cláusulas negociais com condições superiores às condições atuais de trabalho, sempre à luz da Constituição e das normas internacionais.

\section{O PODER DA PARTICIPAÇÃO SINDICAL EM CONFLITOS LABORAIS}

A Declaração Universal de Direitos Humanos (DUDH), nos termos do art. 23.1, atesta que "todo ser humano tem direito ao trabalho, à livre escolha de emprego, a condições justas e favoráveis de trabalho e à proteção contra o desemprego" (ONU, 1948, p. 12). Logo, a proteção por meio de um acordo internacional entre os Estados criou uma institucionalização "de interesses e carências que, em geral, podem e devem ser protegidos e fomentados por direito" (ALEXY, 1999, p. 168).

Uma reivindicação operária, por meio do consenso pelo diálogo, tem por objetivo o bem-estar social e econômico dos trabalhadores com base em um mecanismo regulado por lei intitulado como negociação coletiva. Nela há um embate entre as necessidades econômicas da empresa e a observância de condições de trabalho saudáveis para o alcance dos objetivos coletivos. Em consonância, a DUDH, em seu art. 23.4, ao estabelecer que "todo ser humano tem direito a organizar sindicatos e a neles ingressar para a proteção de seus interesses" (ONU, 1948, p. 13), assegura o equilíbrio de relações naturalmente desiguais, dado o sindicato como ser coletivo que estaria apto a negociar com o ser coletivo empregador (princípio da equivalência dos negociantes).

No entanto, não é sempre que haverá harmonia entre a autonomia coletiva negocial e os direitos fundamentais. Para resolução de um conflito coletivo, a justiça do trabalho usa sua força estatal para o equilíbrio das relações jurídicas entre os particulares. Em sentido contrário,

\footnotetext{
2 Em analogia à teoria da evolução de Darwin, no campo dos direitos sociais as demandas de luta sindical são determinadas pelas interferências legislativas do Estado, em constante transformação, na luta de classe entre trabalhadores e empregadores.
} 
"quando se tem concretização legislativa do conteúdo e alcance das normas de direitos fundamentais, os juízes e tribunais não poderão da legislação se afastar" (TIBALDI; ALVIM, 2018, p. 104).

Os direitos fundamentais são obrigatórios para o convívio na democracia por serem tipicamente ademocráticos: os direitos de liberdade e igualdade desconfiam do processo democrático, pois este representa a maioria parlamentar legitimada para decisão. Por esse motivo, os direitos aos hipossuficientes devem ao menos ser garantidos pela jurisdição constitucional $^{3}$ se constatado o retrocesso social proporcionado pelo processo democrático do Poder Legislativo na aprovação de leis. Como exemplo, nos Estados Unidos existe a prática do "seguro do zelador", baseada na contratação de apólices Coli (seguros de vida) em nome de funcionários de baixo escalão das empresas na execução de atividades de risco, sem a anuência do empregado (SANDEL, 2012, p. 134). Como resultado, a empresa aumenta o risco de acidente no meio ambiente do trabalho pela inobservância de medidas de saúde e segurança, em prol do interesse financeiro conquistado por meio da produtividade desmedida exigida pelo estabelecimento, justificada pela contratação de seguros ao empregado.

Pela jurisdição constitucional no Brasil, o conflito mencionado seria resolvido pela Justiça do Trabalho, que condenaria a empresa em virtude de cláusula contratual abusiva pelo não atendimento do requisito do mútuo acordo (art. 468, CLT $^{4}$ ), mas sim de uma imposição unilateral da empresa. Além desse fundamento, as apólices de valor milionário, para título de antecipação diante de eventual acidente laboral, correspondem a uma condição menos benéfica, já que a própria empresa admite o risco de acidente de trabalho, demonstrando indiferença aos direitos de personalidade do trabalhador, em especial os de saúde e segurança, conforme art. 7, XX, da Carta Magna e art. 155, II, da CLT $^{5}$ (BRASIL, 1988; BRASIL, 1943).

$\mathrm{Na}$ economia, poder-se-ia chamar de um trade-off, ou escolha, entre aprimoramento do meio ambiente do trabalho na redução dos riscos de acidente e a inalterabilidade da gravidade do meio da prestação de serviços para maximização dos lucros. Trata-se de um efetivo embate entre o capital e o trabalho na esfera do direito individual do trabalho. Na seara do direito coletivo, pior ainda seria uma negociação coletiva com o mesmo intuito de precarização das condições mínimas de trabalho, porque a amplitude dos efeitos da norma alcança uma categoria de trabalhadores.

A construção de uma força sindical implica a luta por um padrão setorial de direitos superior ao da legislação trabalhista e pela transação de parcelas apenas de indisponibilidade relativa. Isso significa que direitos de indisponibilidade absoluta, como normas de saúde e segurança do trabalho, jamais poderão ser objeto de negociação, em razão de afrontamento aos princípios da dignidade humana e da valorização do trabalho, conforme o art. $1^{\circ}$, III e IV da Constituição (BRASIL, 1988).

\footnotetext{
3 Por jurisdição constitucional entende-se a resolução de conflitos pelo Poder Judiciário sob fundamentos de direitos resguardados na Constituição de 1988. Todavia, a proteção de direitos fundamentais pela filtragem constitucional nem sempre acontece em razão de sua flexibilização em casos concretos julgados antes mesmo da Reforma Trabalhista. Então, fica necessária a fiscalização dos sindicatos em respeito aos direitos da categoria.

4 Denominado de princípio da inalterabilidade contratual lesiva, nos termos do art. 468 da Consolidação das Leis do Trabalho, "nos contratos individuais de trabalho só é lícita a alteração das respectivas condições por mútuo consentimento e, ainda assim que não resultem, direta ou indiretamente, prejuízos ao empregado, sob pena de nulidade da cláusula infringente desta garantia" (BRASIL, 1943).

5 Consoante o art. 7, XXII, da Constituição, são direitos dos trabalhadores urbanos e rurais a "redução dos riscos inerentes ao trabalho, por meio de normas de saúde, higiene e segurança" (BRASIL, 1988). No mesmo sentido, o art. 157, I, da Consolidação das Leis do Trabalho, incumbe as empresas de "cumprir e fazer cumprir as normas de segurança e medicina do trabalho" (BRASIL, 1943).
} 
Outrossim, pelo princípio da equivalência entre os contratantes coletivos, há igualdade entre os seres coletivos na pactuação das normas, o que implica a responsabilidade social quanto ao atendimento das necessidades da classe trabalhadora. É o sindicado negociando diretamente com a empresa. Em eventual retrocesso social por norma estatal, o sindicato pode e deve intervir por meio de negociações coletivas. Dessa forma, além de o Estado atuar na elaboração de normas, tem-se a participação da categoria trabalhadora na elaboração de normas que possam melhorar suas condições de trabalho.

\section{A PREVALÊNCIA DO NEGOCIADO DIANTE DO PARADIGMA DO TRABALHO DIGNO}

A evolução da proteção dos direitos nas relações de trabalho deu-se em razão das mudanças de paradigmas ao longo da história. Após a queda do Estado Liberal puro em virtude do excesso de formalismos e da inexistência de igualdade material, houve a instauração do Estado Social. Marcado pelas Constituições pioneiras do México (1917) e da Alemanha (1919), esse paradigma conduziu a democratização da sociedade política e civil, com destaque aos avanços das liberdades de associação e reunião de busca de valorização do trabalho humano contra a superexploração.

Nesse sentido, ao contrário da ideologia liberalista, o Estado Social iniciou o "processo de desmercantilização da força de trabalho na economia" (DELGADO, 2015b, p. 134), pela constitucionalização do Direito do Trabalho e da Seguridade Social. Nesse fenômeno, ainda atual, as normas infraconstitucionais de matéria trabalhista são interpretadas à luz de normas e princípios constitucionais. Todavia, a excessiva tributação pelo Estado e a desigual distribuição das riquezas acumuladas instalaram uma crise no Estado-Gestor, já que era difícil subordinar toda a população aos programas sociais estatais de forma isonômica, e corroboraram com a queda do Welfare State (DELGADO, 2015b, p. 30).

Dessa forma, nasceu o paradigma do Estado Democrático ${ }^{6}$, firmado por meio da promulgação da Constituição de 1988 (no Brasil), com a expansão de direitos fundamentais sociais e difusos para a órbita diagonal entre particulares - direitos de defesa de particulares contra particulares, verificada a hipossuficiência de um deles, de grande importância para a relação jurídica laboral.

Nessa lógica, os direitos trabalhistas estão sujeitos ao controle de constitucionalidade, pelo parâmetro de norma social constitucional, ou de convencionalidade, pela decorrência de tratados ou acordos internacionais de direitos humanos, em respeito ao princípio da vedação ao retrocesso social (SARLET, 2014, p. 31). Quanto aos direitos fundamentais constitucionalizados, estes não podem estar sujeitos a alteração pelas maiorias parlamentares devido à natureza de cláusulas pétreas. No entanto, como obter a mesma proteção constitucional para os direitos humanos decorrentes de acordos ou de tratados internacionais?

Os direitos humanos sociais enaltecidos em um tratado ou acordo internacional estão incluídos na cláusula especial de abertura de direitos sociais e dos trabalhadores (SARLET, 2014, p. 31) nos termos do art. $7^{\circ}$, caput, da Carta Magna, ao dispor que "são direitos dos trabalhadores urbanos e rurais, além de outros que visem à melhoria de sua condição social" (BRASIL, 1988, grifo nosso). Logo, aufere-se que os direitos trabalhistas presentes em tratados

\footnotetext{
6 A evolução da proteção de direitos pelo Estado não tem um viés estanque. A Constituição de 1988 é formulada por conceitos liberais e sociais simultaneamente, como a livre iniciativa com preservação da função social e respeitado o meio ambiente do trabalho - art. 170, III, e art. 225, caput da Carta (BRASIL, 1988).
} 
ou acordos internacionais são também "constitucionais" , ainda que não sejam passíveis de controle de constitucionalidade, mas sim de convencionalidade.

No plano internacional de proteção aos direitos trabalhistas, a Declaração de Filadélfia $(1944)^{8}$ aborda quatro princípios fundamentais do Direito Internacional do Trabalho: o trabalho não é uma mercadoria; a liberdade de expressão e de associação são condições indispensáveis a um progresso ininterrupto; a penúria constitui um perigo para a prosperidade geral; há uma estrutura tripartite entre Governo, representantes dos empregadores e dos empregados em decisões democráticas para o bem comum (DELGADO; DELGADO, 2017, p. 69-70).

A Declaração sobre os Princípios e Direitos Fundamentais no Trabalho e seu Seguimento (1998), da Organização Internacional do Trabalho (OIT), reafirma a posição central do trabalhador no cenário internacional a fim de proteger o valor universal ético do trabalho e da dignidade humana. No atual paradigma do trabalho decente, o protagonismo da OIT no combate à superexploração do empregado advém de suas convenções e recomendações, com destaque para o direito coletivo às convenções (n. ${ }^{\circ} 87$ - ainda não ratificada pelo Brasil) e sobre a liberdade de associação e negociação coletiva respectivamente (n. ${ }^{\circ} 98$ da OIT).

Existem quatro princípios constitucionais do trabalho que permeiam o núcleo filosófico, cultural e normativo da Constituição: valorização do trabalho e emprego, justiça social, submissão da propriedade à sua função socioambiental, dignidade da pessoa humana (DELGADO, 2015b). Todos eles criam balizas de padrão mínimo de civilidade nas relações de trabalho em oposição às pressões econômicas do mercado do sistema capitalista.

É exatamente aí que se percebe a necessidade da reconstrução ética do trabalho no atual paradigma. A identidade concebida no meio ambiente do trabalho torna o homem consciente de sua participação no convívio social. A satisfação individual com o trabalho possibilita a proteção social do direito fundamental ao trabalho digno, considerado "sua consciência de liberdade, para que possa se construir e se realizar em sua identidade como sujeito trabalhador" (DELGADO, 2015a, p. 25).

\footnotetext{
7 Tratados ou acordos internacionais que versem sobre direitos humanos têm status de norma constitucional se aprovados pelo quórum de $3 / 5$ em dois turnos de cada casa do Congresso Nacional, conforme art. 5, §3 da Carta Magna (BRASIL, 1988). Caso contrário, apresentam status supralegal - abaixo hierarquicamente apenas das normas da Constituição. Mesmo assim, por considerar a cláusula aberta dos direitos trabalhistas, entende-se a natureza constitucional do acordo ou tratado internacional sobre a matéria por implicitamente estes estarem incluídos no rol de direitos fundamentais.

${ }^{8}$ Formalmente denominada de Declaração sobre os Fins e os Objetivos da Organização Internacional do Trabalho (OIT), fundada em 1919 pelo Tratado de Versalhes.
} 
A Reforma Trabalhista (por meio da Lei $\mathrm{n}^{\circ}$. 13.467/2017), nos artigos 611- $\mathrm{A}^{9}$ e 611-B ${ }^{10}$, modifica a construção hermenêutica consolidada pela Constituição de 1988 ao admitir negociação coletiva em patamares diferenciados aos da previsão legal. Trata-se da prevalência do negociado sobre o legislado como válvula de escape para possibilitar ao empregador a fixação de condições de trabalho piores que as estipuladas pelo parâmetro legal, após pressão do empresariado, com o objetivo de estabelecer normas menos vantajosas a sua categoria lembrando que a matéria negociada precisa estar no rol do art. 611-A, da CLT.

O trabalho digno é o elemento da democracia responsável pela distribuição de poder, pois cria melhores condições de os trabalhadores contribuírem para a sociedade, dada a proteção da indisponibilidade mínima de direitos. A estratégia do empresariado no ataque ao trabalho digno, ao estabelecer hipóteses absolutas de prevalência das negociações sobre a lei, revela a tentativa de concentração de poder e minimização do papel cidadão do trabalhador (PEREIRA, 2018, p. 453).

A solução para evitar a coação sobre os sindicatos dos trabalhadores, além da cláusula especial de abertura, está no art. 9 da CLT, de acordo com o qual "serão nulos de pleno direito os atos praticados com o objetivo de desvirtuar, impedir ou fraudar a aplicação dos preceitos contidos na presente Consolidação" (BRASIL, 1943). Isso enceta a limitação das fronteiras do direito coletivo, pois a supressão de norma estatal pela negociação coletiva se dá por benefícios específicos, caso contrário, será manifesta sua nulidade e o desvirtuamento do direito ao trabalho digno (ESTEVES, 2017, p. 168).

\section{O MÍNIMO EXISTENCIAL DIANTE DO ALARGAMENTO DA AUTONOMIA DA VONTADE COLETIVA}

O mínimo existencial indica a proteção estatal obrigatória de direitos essenciais para a dignidade humana, pois é "uma espécie de limites dos limites dos direitos fundamentais, constituindo critério material para o controle de legitimidade constitucional de excesso de intervenção em direito social e mesmo na dignidade da pessoa humana" (SARLET, 2014, p. 49). Esse patamar civilizatório mínimo está composto por normas constitucionais em geral,

\footnotetext{
9 O art. 611-A da CLT prevê a prevalência do negociado sobre o legislado em relação aos seguintes direitos: jornadas de trabalho; banco de horas; intervalo intrajornada com respeito ao mínimo de 30 minutos; adesão ao programa seguro-emprego; plano de cargos, salários e funções; representante dos trabalhadores no local de trabalho; teletrabalho, regime de sobreaviso e trabalho intermitente; remuneração por produtividade; modalidade de registro de jornada; prêmios; participação nos lucros.

${ }^{10} \mathrm{O}$ art. 611-B da CLT prevê as matérias que não poderão ser suprimidas ou reduzidas por convenção ou acordo coletivo: carteira de trabalho; seguro desemprego; FGTS; salário mínimo; décimo terceiro salário; remuneração do trabalho noturno superior ao diurno; proteção do salário; salário-família; repouso semanal remunerado; horas extraordinárias com no mínimo $50 \%$ da hora normal; número de dias de férias; férias com um terço da remuneração; licença maternidade de cento e vinte dias; licença paternidade nos termos da lei; proteção ao mercado de trabalho da mulher; aviso prévio proporcional de no mínimo 30 dias; normas de saúde, higiene e segurança do trabalho; remuneração para atividades penosas, insalubres e perigosas; aposentadoria; seguro contra acidente de trabalho; prazo de prescrição; proibição de discriminação do trabalhador com deficiência; proibição de trabalho noturno, perigoso ou insalubre aos menores de 18 anos e de qualquer trabalho aos menores de 16 anos, salvo na condição de aprendiz a partir dos quatorze; medidas legais de proteção da criança e do adolescente; liberdade de associação sindical e de não ter descontado do salário qualquer parcela em convenção ou acordo coletivo sem ausência do trabalhador; direito de greve e definição das atividades essenciais; tributos e outros créditos de terceiros; disposição sobre o trabalho da mulher e proteção à maternidade.
} 
ressalvadas as hipóteses de flexibilização dos incisos VI, XIII e XIV do art. 7 da Constituição ${ }^{11}$; as normas de tratados e convenções internacionais assinadas pelo Brasil e as normas infraconstitucionais que asseguram patamares de cidadania ao indivíduo (DELGADO, 2012, p. 116).

A preservação do mínimo existencial em normas coletivas é averiguada apenas na instância prática de casos concretos. Então, o tipo de categoria juntamente ao princípio da norma mais favorável e à natureza de direito indisponível podem guiar o Juiz ou Procurador do Trabalho a perceber alguma margem de violação do mínimo existencial. Se as normas coletivas negociadas forem de exagerada flexibilização, ou seja, desnaturarem os direitos pertencentes à cláusula especial de abertura, é porque há violação ao núcleo mínimo, cabendo ação de nulidade da cláusula de norma coletiva, cujo efeito será erga omnes (LOCATELLI, 2017, p. 125).

Fundada na autonomia sindical (art. 8, inciso I, da Constituição de 1988), a autonomia coletiva é a capacidade de os sindicatos estabelecerem um sistema de direitos de proteção aos trabalhadores. Trata-se, assim, da limitação à liberdade sindical na elaboração de normas coletivas, dado o princípio da criatividade jurídica da negociação coletiva. Logo, os sindicatos estão livres para negociar os direitos da categoria desde que promovam a melhoria da condição social.

Todavia, nos termos do art. $8, \S 3$, da CLT, a Justiça do Trabalho somente examinará as negociações coletivas quanto aos elementos essenciais do negócio jurídico (art. 104 do Código Civil), em prol do princípio da intervenção mínima na autonomia da vontade coletiva prevista no texto da lei. A compatibilidade do conteúdo de uma negociação jurídica com a Constituição e as normas internacionais não pode ser enquadrada no inciso II do art. 104 do Código Civil - "objeto lícito, possível, determinado ou determinável” -, já que a celebração de direitos trabalhistas não se limita à previsão legal e à livre escolha dos contratantes (como no direito comum), mas ao respeito da norma mais favorável, independentemente da hierarquia normativa, em uma eventual colisão de interesses entre empregador e trabalhador. Cabe ao Juiz e ao Procurador do Trabalho a atividade fiscalizatória das negociações em seu conteúdo e sua prevalência sobre a lei, se mais favoráveis.

Esse escudo da intervenção mínima na autonomia da vontade coletiva inviabiliza apenas formalmente a melhoria da condição social dos trabalhadores prevista no art. 7, caput, da Carta Magna, visto que a via interpretativa do direito é a Constituição para a legislação infraconstitucional, e não o contrário. Logo, é papel do magistrado verificar a compatibilidade da cláusula coletiva às de melhoria social e aos direitos fundamentais de natureza constitucional. Além disso, não é atribuição de lei ordinária interferir na competência institucional do Ministério Público de fiscal da ordem jurídica e elencar vícios materiais nas normas coletivas, nos termos do art. 127 da Carta Maior.

A Constituição, nos moldes do art. 7, inciso XXII, não prevê a flexibilização via negociação coletiva de normas de saúde, higiene e segurança em razão da natureza jus cogens, portanto, sua irrenunciabilidade é absoluta. Os direitos relacionados à duração do trabalho e aos intervalos, na visão jurisprudencial anterior à reforma, tinham reconhecidas a natureza da norma jus cogens, pois "se a gestão do tempo de trabalho é condicionada apenas às demandas da

\footnotetext{
${ }^{11}$ Refere-se às hipóteses de flexibilização trabalhista, presentes no art. 7, CF: VI - irredutibilidade do salário, salvo disposto em convenção ou acordo coletivo; XIII - duração do trabalho normal não superior a oito horas diárias e quarenta e quatro semanais, facultada a compensação de horários e a redução da jornada, mediante acordo ou convenção coletiva de trabalho; XIV - jornada de seis horas para o trabalho realizado em turnos ininterruptos de revezamento, salvo negociação coletiva.
} 
produção, o trabalhador se torna completamente refém do empregador, que passa a se apropriar do tempo livre do empregado" (PEREIRA, 2018, p. 462).

Em contrariedade à previsão constitucional, o art. 611-B, parágrafo único, da CLT retira as regras sobre duração do trabalho e intervalos daquelas consideradas normas de saúde, higiene e segurança do trabalho, o que permite a regulação desses direitos por negociação coletiva. Isso significa maior tempo à disposição do trabalhador e frustação da realização de projetos de vida pessoal e familiar, o que aumenta o risco de acidente e adoecimento no trabalho.

Mais uma vez, o direito fundamental ao trabalho digno foi mutilado pelo interesse econômico do empregador, tendo em vista o esvaziamento do conceito de segurança e medicina do trabalho, responsáveis pelo equilíbrio no ambiente de trabalho aos serviços de duração exaustiva. $\mathrm{O}$ intervencionismo estatal sempre foi necessário devido à concentração de sindicatos em algumas regiões em detrimento de outras e eventuais desvios de finalidade quanto à luta pelos direitos da categoria (ESTEVES, 2017, p. 169).

O legislador, ao implantar a prevalência do negociado sobre o legislado, justifica por motivos econômicos a concessão de maiores oportunidades de preservação do trabalho ou a fuga da judicialização. Contudo, flexibilizar direitos pelas negociações "para aumentar o número de vagas de trabalho não deu muito certo em países como a Espanha, Colômbia, Argentina, Chile" (ESTEVES, 2017, p. 174).

A negociação, em tese, tem por objetivo a paridade de armas e condições equivalentes de negociação. Porém, diante de crises econômicas, pode ser bastante perigoso ampliar o poder normativo dos sindicatos para a sobrevivência do capitalismo e, por consequência, a diminuição de salário, o aumento de jornada e a redução das condições de higiene no meio laboral (SOUZA, 2017a, p. 179).

A função natural da negociação coletiva é otimizar a regulação das relações do trabalho, e não suprimir direitos básicos dos trabalhadores, existindo na autonomia coletiva uma espécie de moldura, com limites e espaços para normatização. Assim, consoante o princípio da adequação setorial negociada, as normas autônomas prevalecem sobre as heterônomas apenas quando "implementam um padrão setorial de direitos superior ao padrão geral oriundo da legislação aplicável, e quando transacionam setorialmente parcelas justrabalhistas de indisponibilidade apenas relativa" (TIBALDI; ALVIM, 2018, p. 100).

Outro dispositivo, o art. 444, parágrafo único, da CLT, admite a livre estipulação prevista no art. 611-A quando o empregado portar curso de Ensino Superior e receber salário mensal igual a duas vezes o limite máximo dos benefícios do regime da Previdência Social. Essa definição de hiperempregado explicita a inconstitucionalidade do dispositivo em decorrência da criação de critérios objetivos de renda e escolaridade como fatores de separação entre o empregado vulnerável e aquele que tem maior poder de barganha, porquanto o que ditará a proporcionalidade da proteção do Estado ao empregado será a subordinação jurídica estrutural e o excessivo tempo à disposição na relação de emprego.

A questão não se refere unicamente ao conhecimento escolar e à renda na aptidão de celebração do negócio coletivo, mas à capacidade de percepção de uma situação mais ou menos favorável no que tange à relação de emprego, impedindo a verdadeira autonomia da vontade do empregado hipersuficiente (BORBA, 2018).

Se de um lado se amplia o poder sindical - pela prevalência do negociado -, de outro se retira a obrigatoriedade da contribuição sindical (art. 579, CLT), promovendo um enfraquecimento do poder de barganha e a requisição de novos direitos. Por resultado, para o 
sindicato manter-se vivo, "a cláusula do dia será a implementação via negociação sindical da contribuição que lhe mantém ativo, ainda que isso implique ao empregador a renúncia a direitos sociais do trabalhador" (SOUZA, 2017b, p. 251-252).

Assim, o mínimo existencial tem relação intrínseca com a proibição ao retrocesso, conhecida como efeito cliquet $^{12}$ dos direitos fundamentais. Caso as condições essenciais na relação de emprego digno sejam extintas, haverá o enfraquecimento de direitos até então conquistados. Dessa forma, o direito coletivo, sob o prisma da reforma trabalhista, desprotege o bem jurídico irreparável da saúde e segurança do trabalhador.

\section{A PREVALÊNCIA DO NEGOCIADO PARA REDUZIR DIREITOS E A SOBREVIVÊNCIA DO SINDICALISMO}

$\mathrm{Na}$ teoria geral do direito, a hierarquia das normas se caracteriza como rígida e inflexível, com fundamento de validade na Constituição. A pirâmide normativa tem em seu vértice a Carta Magna, seguida das normas infraconstitucionais (leis complementares, leis ordinárias, leis delegadas e medidas provisórias). Todavia, a hierarquia das normas no direito do trabalho segue o princípio da norma mais favorável, dando plasticidade à pirâmide normativa.

A aplicação da norma no caso concreto das relações laborais será a mais favorável ao trabalhador, independentemente de sua hierarquia. É possível criar fontes normativas, a exemplo das normas coletivas, a fim de criar condições mais favoráveis que as apresentadas na Constituição, o que seria impossível de se imaginar no direito comum. Isso significa que uma norma coletiva pode ser condição mais benéfica do que o patamar mínimo civilizatório alcançado pela legislação em prol da valorização do trabalho e da dignidade humana.

Como um desmembramento da norma mais favorável, a teoria do conglobamento ${ }^{13}$ "compara as fontes e aplica a que, em seu conjunto, for mais favorável ao empregado, excluindose as demais" (SOUZA JÚNIOR, 2017, p. 343). A visão completa do instrumento normativo para a escolha dentre as negociações possíveis remeteria ao critério da norma mais benéfica/ favorável ao empregado à luz do caso concreto.

No entanto, a Lei n. ${ }^{\circ} 13.467 / 17$ (Reforma Trabalhista), no art. 620 da CLT, relativizou o princípio da norma mais favorável e tornou a prevalência absoluta do acordo coletivo (ACT) sobre a convenção coletiva de trabalho (CCT). Ambas são espécies de normas coletivas usualmente firmadas por sindicatos, tendo como elemento diferenciador as categorias sindicais. Enquanto o acordo é celebrado entre a categoria profissional e a empresa, a convenção é feita entre a categoria profissional e a econômica. Assim, será que diferenciar de modo estático qual norma sempre prevalecerá pode caracterizar violação ao princípio da norma mais favorável?

Conforme já mencionado, esse princípio está inserido na cláusula especial de abertura do art. 7, caput, da Constituição Federal ("além de outros que visem à melhoria de sua condição social"), além das normas internacionais de direitos humanos de progressividade social vigentes no país. A alteração legislativa aponta para a regressão do patamar civilizatório mínimo, visto que o ACT poderá fixar cláusulas supressoras ou restritivas de direitos contidas na CCT da categoria.

\footnotetext{
${ }^{12}$ Por esse efeito, os direitos fundamentais trabalhistas não podem retroagir, apenas avançar na proteção dos trabalhadores, o que ratifica o princípio da vedação ao retrocesso social.

${ }^{13}$ Para exemplificação, pode haver cláusulas de acordo coletivo com participação nos lucros e seguro de vida mais vantajosas que uma convenção coletiva com apenas a vantagem sobre horas extras. Com a aplicação da teoria do conglobamento, o acordo coletivo prevalece e deve ser aplicado, afastando a convenção em seu todo.
} 
$\mathrm{O}$ art. 7, caput, da Constituição assume "a lógica da justiça social, a partir da efetiva distribuição de renda, colaborando, assim, para a construção do desenvolvimento social que deve ser necessariamente pautado na redução das desigualdades sociais" (SILVA, 2017, p. 248).

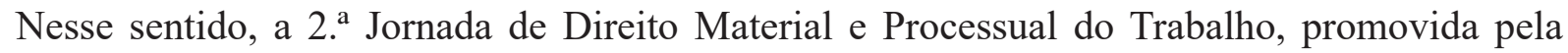
Associação dos Magistrados da Justiça do Trabalho (Anamatra) em 2018, aprovou o Enunciado Aglutinado n. ${ }^{\circ}$ 3, da Comissão 3, que aborda a continuidade da aplicação do princípio da norma mais favorável e a teoria conglobante, ainda que na vigência da reforma.

Em outra novidade da reforma, o art. 614, §3, da CLT manteve o lapso temporal de dois anos de vigência das negociações coletivas, mas expressamente vedou a ultratividade, permitida até então pela Súmula n. ${ }^{\circ} 277$ do Tribunal Superior do Trabalho (TST) ${ }^{14}$. Anterior a essa legislação, em outubro de 2016, na Arguição de Descumprimento de Preceito Fundamental (ADPF) n. ${ }^{\circ}$ 323-DF, o Supremo Tribunal Federal, sob relatoria do Ministro Gilmar Mendes, suspendeu por medida liminar os efeitos da Súmula. A ultratividade da norma coletiva era a vigência após o lapso de dois anos até que nova negociação coletiva fundasse regras distintas e mais benéficas do que aquelas já negociadas para a categoria. Sem o efeito da ultratividade, celebrada a norma coletiva, esta é limitada pela duração de seu prazo legal de dois anos.

A retirada da ultratividade das negociações coletivas desestimula o empregador à negociação, pois sua mera inércia é suficiente para a terminação das cláusulas negociais coletivas já pactuadas (DELGADO; DELGADO, 2017, p. 272). Pela ultratividade, a empresa teria interesse em negociar a todo instante, tendo em vista que se não celebrasse nova norma coletiva modificando as cláusulas de norma anterior, essa condição, mesmo fora do prazo de dois anos da negociação, permaneceria. Ainda que trouxesse insegurança jurídica quanto ao prolongamento da eficácia da negociação para além do termo final pré-fixado, a ultratividade impedia o retrocesso social dos direitos conquistados.

Em exemplo da aplicação da ultratividade, quando ainda não vedada pela reforma, o TST julgou procedente recurso de revista para o pagamento de anuênio e quinquênio previstos em norma coletiva de prazo legal superior de dois anos, dada a integração dessas parcelas no contrato de trabalho do empregado e que sua supressão implica em prejuízo ao empregado.

O artigo 4. ${ }^{\circ}$ da Convenção n. ${ }^{\circ} 98$ (OIT, 1949), relativa à aplicação dos princípios do direito de organização e de negociação coletiva, enceta que

deverão ser tomadas, se necessário for, medidas apropriadas às condições nacionais para fomentar e promover o pleno desenvolvimento e utilização de meios de negociação voluntária entre empregadores e organizações de trabalhadores, com o objetivo de regular, por meio de convenções coletivas, os termos e condições de emprego.

O Enunciado Aglutinado n. ${ }^{o}$ 13, da Comissão 3, da 2. Jornada de Direito Material e Processual do Trabalho, também expôs a incompatibilidade da vedação da ultratividade frente à Constituição.

É notória a resistência do princípio da norma mais favorável para as negociações coletivas em observação ao mínimo existencial de direitos já conquistados ao trabalhador. Nesse sentido, a interpretação dos artigos 614, §3 (vedação à ultratividade), e 620 da CLT (sobreposição do ACT sobre a CCT) deverá ser feita conforme a Constituição, já que o art. 7,

\footnotetext{
${ }^{14}$ Súmula n. ${ }^{\circ} 277$, TST: "as cláusulas normativas dos acordos coletivos ou convenções coletivas integram os contratos individuais de trabalho e somente poderão ser modificadas ou suprimidas mediante negociação coletiva de trabalho". Nela, está inserida a aderência limitada por revogação, ou seja, seria necessária uma nova negociação para modificar ou suprimir vantagens a uma categoria auferida em negociação anterior.
} 
caput, da Carta é claro ao permitir uma ampliação de direitos apenas em favor da construção social do empregado no meio ambiente de trabalho, e não para sua precarização.

As modificações implementadas pela reforma trabalhista fazem surgir dúvidas a respeito da sobrevivência dos sindicatos no sistema de unicidade sindica ${ }^{15}$. Sem estabilidade financeira no orçamento da estrutura sindical da categoria profissional, antes permitida pela contribuição obrigatória, como os sindicatos poderão se organizar para a celebração de negociações coletivas com a empresa ou categoria econômica? E quando alcançada a negociação, isso não significa a implementação do direito nos contratos de trabalho após os dois anos pela vedação à ultratividade?

E mais: os sindicatos ficam empenhados em celebrar somente acordos coletivos, em razão da especialidade, se comparada a uma convenção. A natureza ampla da CCT pode originar normas descompromissadas com meios ambientes laborais diversos na mesma categoria. Uma empresa firmando norma coletiva com um sindicato profissional por meio do ACT enceta a preocupação da categoria com as realidades dos empregados que laboram naquela empresa específica, porém não se pode partir da premissa de que a norma mais específica é sempre a melhor a ser firmada. A inflexibilidade do art. 620 da CLT, em prejuízo da norma mais favorável, pode contribuir para a inobservância da realidade laboral.

\section{CONCLUSÃO}

É compreensível afirmar o atentado ao direito fundamental ao trabalho digno cometido pela reforma trabalhista sob a óptica do direito coletivo, em razão da mudança antecipar quais serão os direitos transacionáveis sem se observar o caso concreto (art. 611-A, CLT). No entanto, o giro hermenêutico deve-se dar sempre à luz da Constituição: uma transação de direitos que não visem à melhoria nas condições de trabalho ao empregado será plenamente nula.

A prevalência do negociado sobre o legislado não é um ditame absoluto, mas aplicável apenas quando houver a preservação do mínimo existencial, em convergência ao princípio da adequação setorial coletiva. Apesar de aparente ampliação das possibilidades de uso do poder normativo dos sindicatos, é dificultosa a real efetivação desse poder, quando as flexibilizações trazidas pela lei são menos benéficas que as atuais.

A vedação ao retrocesso social e a norma mais favorável funcionam como balizas para a sobrevivência sindical em virtude da realização de negociações para além de lícitas, mas de condição sempre mais benéfica para a categoria - se considerada a última transação realizada. Normas coletivas que protejam a categoria são determinantes para a sobrevivência de sindicatos.

Para finalizar, éimportante reforçar que as modificações trazidas pela reforma trabalhista precisam ser interpretadas consoante os princípios constitucionais da valorização do trabalho humano e da dignidade humana, evitando, assim, o retrocesso social e o desaparecimento dos sindicatos.

\section{REFERÊNCIAS}

AGUIAR, Antônio Carlos. O negociado sobre o legislado e a função do sindicato. Revista do Advogado, São Paulo, v. 38, n. 137, p. 7-16, mar. 2018.

\footnotetext{
${ }^{15}$ Nesse sistema, cada categoria (profissional ou econômica) pode ter representação sindical limitada a um sindicato por base territorial mínima de um município, nos termos do art. 8, II, da Constituição.
} 
ALEXY, Robert. Direitos fundamentais, balanceamento e racionalidade. Ratio Juris, v. 16, n. 2, p. 131-140, jun. 2003.

Direitos fundamentais no Estado Constitucional Democrático: para relação entre direitos do homem, direitos fundamentais, democracia e jurisdição constitucional. Tradução de Luís Afonso Heck. Revista de Direito Administrativo, Rio de Janeiro, n. 217, p. 55-66, jul./set. 1999.

ANAMATRA - Associação Nacional dos Magistrados da Justiça do Trabalho. 2. ${ }^{\text {a Jornada de }}$ Direito Material e Processual do Trabalho. XIX Congresso Nacional dos Magistrados da Justiça do Trabalho, 19., Belo Horizonte, 2018.

BORBA, Camila Sailer Rafanhim de. A indisponibilidade individual na tutela coletiva trabalhista. Curitiba: Ithala, 2018.

BRASIL. Constituição da República Brasileira da 1988. Brasília, DF, 1988. Disponível em: http://www.planalto.gov.br/ccivil_03/constituicao/constituicao.htm. Acesso em: 22 jun. 2020.

Decreto-lei n. ${ }^{\circ}$ 5.452/1943. Aprova a Consolidação das Leis do Trabalho. Brasília, DF, 1943. Disponível em: http://www.planalto.gov.br/ccivil_03/decreto-lei/del5452.htm. Acesso em: 22 jun. 2020.

Lei n. ${ }^{0}$ 13.467/2017. Altera a Consolidação das Leis do Trabalho (CLT), aprovada pelo Decreto-Lei ${ }^{\circ} 5.452$, de $1^{\circ}$ de maio de 1943, e as Leis $n^{\circ} 6.019$, de 3 de janeiro de 1974, 8.036, de 11 de maio de 1990, e 8.212, de 24 de julho de 1991, a fim de adequar a legislação às novas relações de trabalho. Brasília, DF, 2017. Disponível em: http://www.planalto.gov.br/ ccivil_03/_ato2015-2018/2017/lei/113467.htm. Acesso em: 22 jun. 2020.

Projeto de Lei n. ${ }^{\mathbf{1 3 4}}$ 13001. Altera o artigo 618 da Consolidação das Leis do Trabalho - CLT. (Estabelece a prevalência de convenção ou acordo coletivo de trabalho sobre a legislação infraconstitucional). Brasília, DF, 2017. Disponível em: http://www.planalto.gov.br/ccivil_03/_ ato2015-2018/2017/lei/113467.htm. Acesso em: 22 jun. 2020.

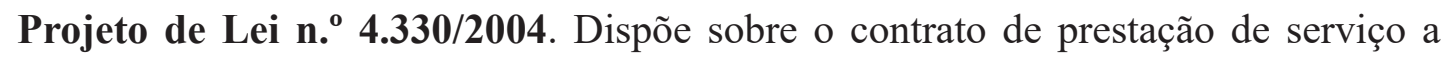
terceiros e as relações de trabalho dele decorrentes. Brasília, DF, 2004. Disponível em: https:// www.camara.leg.br/proposicoesWeb/fichadetramitacao?idProposicao=267841. Acesso em: 22 jun. 2020.

Projeto de Lei n. ${ }^{0}$ 6.787/2016. Altera o Decreto-Lei $n^{\circ} 5.452$, de $1^{\circ}$ de maio de 1943 Consolidação das Leis do Trabalho, e a Lei $n^{0}$ 6.019, de 3 de janeiro de 1974, para dispor sobre eleições de representantes dos trabalhadores no local de trabalho e sobre trabalho temporário, e dá outras providências. Brasília, DF, 2016. Disponível em: https://www.camara.leg.br/ proposicoesWeb/fichadetramitacao?idProposicao=2122076. Acesso em: 22 jun. 2020.

DELGADO, Gabriela Neves. Direito fundamental ao trabalho digno. 2. ed. São Paulo: LTr, 2015a.

DELGADO, Gabriela Neves; DELGADO, Mauricio Godinho. A reforma trabalhista no Brasil: com os comentários à Lei n. ${ }^{\circ}$ 13.467/2017. São Paulo: LTr, 2017.

DELGADO. Maurício Godinho. Constituição da República, Estado Democrático de Direito e Direito do Trabalho. In: DELGADO, Gabriela Neves et al. Direito constitucional do trabalho: princípios e jurisdição constitucional do TST. São Paulo: LTr, 2015 b.

Curso de direito do trabalho. 11. ed. São Paulo: LTr, 2012.

. Curso de direito do trabalho. 18. ed. São Paulo: LTr, 2019. 
. Direitos fundamentais na relação de trabalho e o novo expansionismo juslaboralista: o conceito de subordinação estrutural. In: FREDIANI, Yone; ALVARENGA, Rúbia Zanotelli de (org.). Direitos fundamentais nas relações de trabalho. São Paulo: LTr, 2015c.

ESTEVES, Alan da Silva. Reforma Trabalhista Brasileira de 2017 e o direito coletivo do trabalho: ideias para justificar a prevalência do negociado sobre o legislado. Revista dos Tribunais Online, v. 984, p. 163-188, out. 2017.

GUSTIN, Miracy Barbosa de Sousa; DIAS, Maria Tereza Fonseca. Repensando a pesquisa jurídica: teoria e prática. 2. ed. Belo Horizonte: Del Rey, 2006.

LOCATELLI, Aguinaldo. Negociado sobre o legislado: critérios e elementos de validade à luz do ordenamento jurídico. Revista de Direito do Trabalho, v. 184, p. 121-142, dez. 2017.

LOGUERCIO, Eynard José. LOPES, Antônio Fernando Megale. O negociado sobre o legislado: suprema injustiça e demolição do sistema protetivo trabalhista. In: RAMOS, Gustavo Teixeira et al. (coord.). O Golpe de 2016 e a Reforma Trabalhista: narrativas de resistência. Bauru: Canal 6, 2017.

OIT - Organização Internacional do Trabalho. Convenção n. ${ }^{0}$ 98/1949. Direito de Sindicalização e de Negociação Coletiva. Disponível em: https:/www.ilo.org/brasilia/temas/ normas/WCMS_235188/lang--pt/index.htm. Acesso em: 23 jun. 2020.

ONU - Organização das Nações Unidas. Declaração Universal dos Direitos Humanos. 1948. Disponível em: https://nacoesunidas.org/wp-content/uploads/2018/10/DUDH.pdf. Acesso em: 23 jun. 2020.

PEREIRA, Ricardo José Macedo de Britto. Prevalência do negociado sobre o legislado e a negociação coletiva na nova lei: examinando limites e alcance constitucionais. In: COSTA, Ângelo Fabiano Farias da et al. (org.). Reforma Trabalhista na visão de procuradores do trabalho, Ed. Salvador: Juspodivm, 2018.

SANDEL, Michael J. O que o dinheiro não compra: os limites morais do mercado. Tradução de Clóvis Marques. Rio de Janeiro: Civilização Brasileira, 2012.

SARLET. Ingo Wolfgang. Os direitos dos trabalhadores como direitos fundamentais na constituição federal brasileira de 1988. In: SARLET, Ingo Wolfgang; MELLO FILHO, Luiz Philippe Vieira de; FRAZÃO, Ana de Oliveira (Coord.). Diálogos entre o Direito do Trabalho e o Direito Constitucional: estudos em homenagem a Rosa Maria Weber. São Paulo: Saraiva, 2014.

SILVA, Mayana Macedo Fernandes da. Da prevalência do negociado sobre o legislado. In: ZIMMERMANN, Cirlene Luiza. (coord.). Reforma Trabalhista Interpretada: Lei n. ${ }^{\circ}$ 13.467/2017. Caxias do Sul: Plenum, 2017.

SOUZA, Rodrigo Trindade de. Negociado sobre legislado: o mito de Ulisses e as sereias. In: FELICIANO, Guilherme Guimarães; TREVISO, Marco Aurélio Marsiglia; FONTES, Saulo Tarcísio de Carvalho (org.). Reforma Trabalhista: visão, compreensão e crítica. São Paulo: LTr, 2017a.

SOUZA, Roberta de Oliveira. Análise do negociado versus o legislado: perspectivas doutrinária, jurisprudencial e orçamentária da reforma trabalhista considerando os argumentos favoráveis e contrários à constitucionalidade da Lei 13.467 de 2017. Revista dos Tribunais, v. 985, p. 243-261, nov. 2017 b. 
SOUZA JÚNIOR, Antônio Umberto de et al. Reforma Trabalhista: análise comparativa e crítica da Lei n. ${ }^{\circ}$ 13.467/17. São Paulo: Rideel, 2017.

STUDART, Ana Paula Didier. O negociado sobre o legislado: uma análise dos aspectos positivos e negativos dessa mudança. Revista de Direito do Trabalho, São Paulo v. 197, ano 5, p. 33-45, jan. 2019.

TIBALDI, Saul Duarte; ALVIM, Victor Lucas. As negociações coletivas trabalhistas e a eficácia dos direitos fundamentais nas relações entre os particulares. Revista de Direito do Trabalho, São Paulo, v. 188, ano 44, p. 89-113, abr. 2018.

TST - Tribunal Superior do Trabalho. ADPF n. ${ }^{\text {o } 323 S T F / 2014 . ~ D i s p o n i ́ v e l ~ e m: ~ h t t p s: / / w w w . ~}$ trt6.jus.br/portal/jurisprudencia/temas-e-precedentes/14472. Acesso em: 23 jun. 2020.

TST - Tribunal Superior do Trabalho. Súmula n. ${ }^{\circ}$ 277/1988. Disponível em: https://www.legjur. com/sumula/busca?tri=tst\&num=277\#topo. Acesso em: 23 jun. 2020.

Recebido em maio de 2019

Aceito em fevereiro de 2020 